\title{
SUPRASTERNAL EPIDERMOID- A RARE CASE REPORT
}

\author{
Kamal Pandyan ${ }^{1}$, Abhilash Shambulingegowda ${ }^{2}$
}

${ }^{1}$ Surgeon, Department of ENT, KGP Hospital, Vinobanagar, Shimoga.

2Surgeon, Department of ENT, All India Institute of Speech and Hearing, Manasagangothri, Mysuru.

\section{ABSTRACT}

\section{BACKGROUND}

Swelling in the head and neck region is always a diagnostic dilemma. Approximately, $7 \%$ of the swellings in head and neck regions turn out to be cases of epidermoid or dermoid cysts. Epidermoid cysts are known as benign, squamous epithelium-lined cystic spaces, they may occasionally contain skin adnexa (true dermoid cyst) or derivatives from all 3 germ layers (teratoma). We here present a case of a suprasternal cystic swelling in a 5-year-old girl, present since 3 years. The mass was soft, mobile and nontender. FNAC and USG were suggestive of a dermoid cyst. The cyst was excised under general anaesthesia. Histopathological examination confirmed it to be an epidermoid cyst. There was no recurrence over 6 months followup. This is an interesting case of epidermoid cyst in the suprasternal notch which is a very rare presentation and only few cases have been reported in literature.

\section{KEYWORDS}

Epidermoid Cyst, Histopathology, Head and Neck.

HOW TO CITE THIS ARTICLE: Pandyan K, Shambulingegowda A. Suprasternal epidermoid- A rare case report. J. Evolution Med. Dent. Sci. 2017;6(33):2776-2779, DOI: 10.14260/Jemds/2017/598

\section{BACKGROUND}

The epidermoid cyst or infundibular cyst represent the most common cutaneous cysts, frequently seen on the face, scalp and trunk.[1] It results from the proliferation of epidermal cells within a circumscribed space of the dermis. Epidermoid cysts occur at any age; however, most commonly arise in the third and fourth decades of life. This is an interesting case of a epidermoid cyst in the suprasternal notch which is a very rare presentation and only few cases have been reported in literature.

\section{CASE REPORT}

A 5-year-old girl presented with a swelling in the suprasternal region since 3 years. The swelling was increasing in size, with dull aching pain since 3 weeks. Patient was on conservative treatment for the past 1 year, but there was no improvement. No medical history of upper respiratory tract infection, no history of fever, loss of weight, odynophagia, hoarseness of voice, shortness of breath or nasal obstruction. No history of trauma or previous surgical procedures. No similar complaints in the family.

Examination of the neck revealed a $2.5 \mathrm{~cm} \times 2 \mathrm{~cm}$ mass in the suprasternal region. On palpation, the mass was firm, not tender, there was no ulceration or discoloration of overlying skin. The lower margin of the mass was difficult to palpate. No movement with swallowing or protrusion of the tongue. Bilateral cervical lymphadenopathy was present. Systemic examination was unremarkable.

Routine lab investigations such as complete blood count, renal and liver functions, all were found to be within normal limits. Fine needle aspiration cytology (FNAC) was performed and reported as suggestive of a dermoid cyst.

Financial or Other, Competing Interest: None.

Submission 08-03-2017, Peer Review 12-04-2017,

Acceptance 18-04-2017, Published 24-04-2017.

Corresponding Author:

Dr. Abhilash Shambulingegowda,

Door No. 870, 24th Cross, $4^{\text {th }}$ Main,

Vidyaranyapuram, Mysuru-570008.

E-mail:dr.abhilashs@yahoo.in

DOI: $10.14260 /$ jemds/2017/598

\section{(c) (i) $(3)$}

High resolution Ultrasonography (USG) of the neck shows a well-defined cyst in the subcutaneous plane measuring 10 $\mathrm{mm} \times 6 \mathrm{~mm}$ in the suprasternal region showing hypoechoic content.

Multiple lymph nodes in the bilateral upper and mid jugular chain, largest one measuring $7 \mathrm{~mm}$ on both sides, normal fatty hilum were seen.

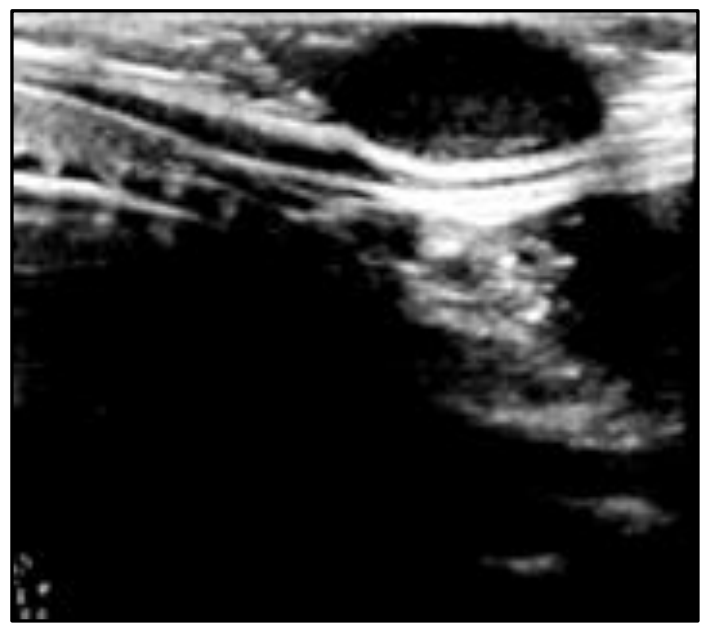

Figure 1. USG Showing the Cyst in the Suprasternal Area

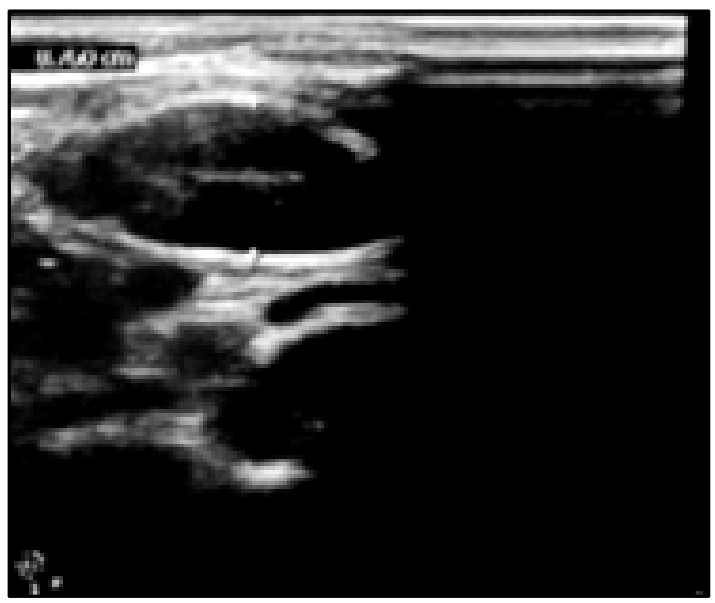

Figure 2. Showing the Enlarged Lymph nodes 
The child was posted for surgery under general anaesthesia and the cyst was removed. A transverse incision of $2 \mathrm{~cm}$ was placed above the sternum, dissecting around the capsule of mass. The lower margin was accessed by hyperextension of the neck and retraction of the mass upwards. The mass was inflamed and could not be resected en bloc with intact capsule due to adhesion but removed completely without any residual tissue. It measured about $2.5 \mathrm{~cm} \times 2 \mathrm{~cm}$.

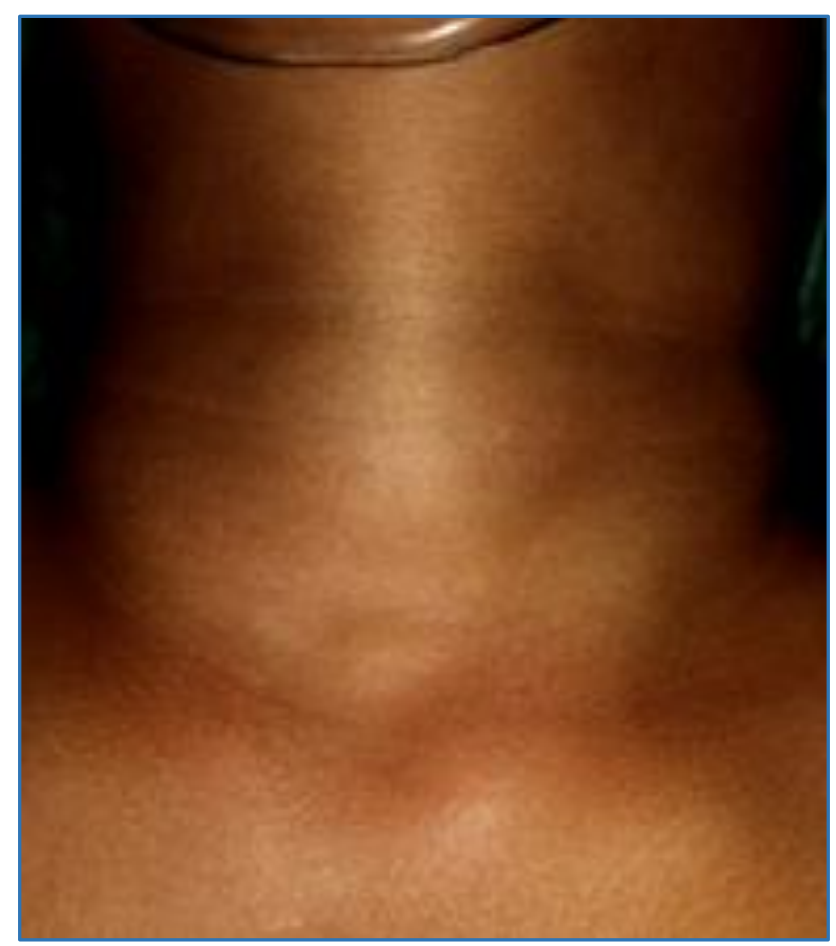

Figure 3. Swelling is Prominet on Hyperextension of the Neck

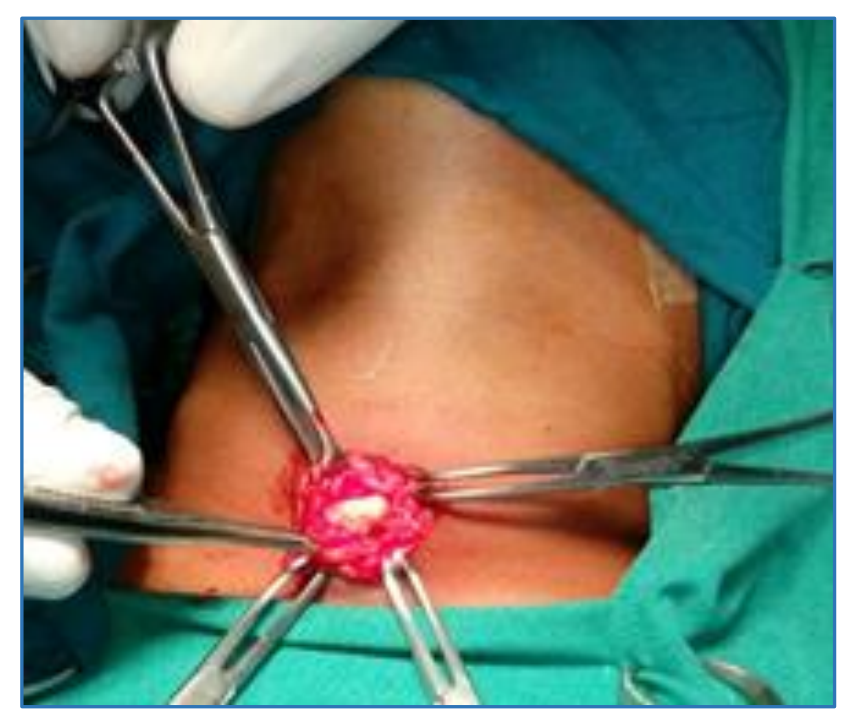

Figure 4. After Superficial Dissection, the Infected Cyst was Identified

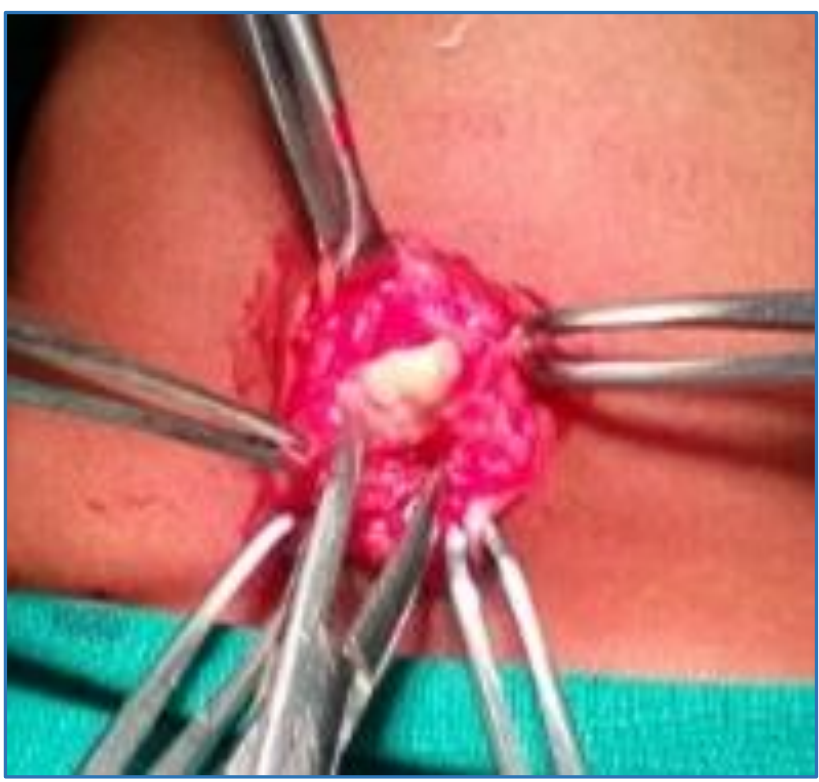

Figure 5. Swelling of size $2.5 \mathrm{~cm} \mathrm{X2 \textrm {cm }}$

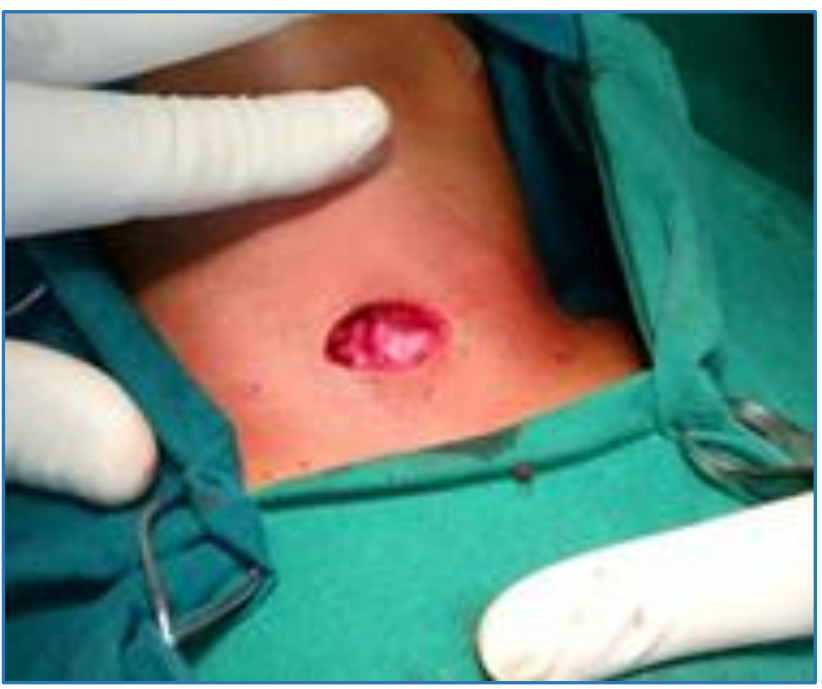

Figure 6. After Resection of the Swelling

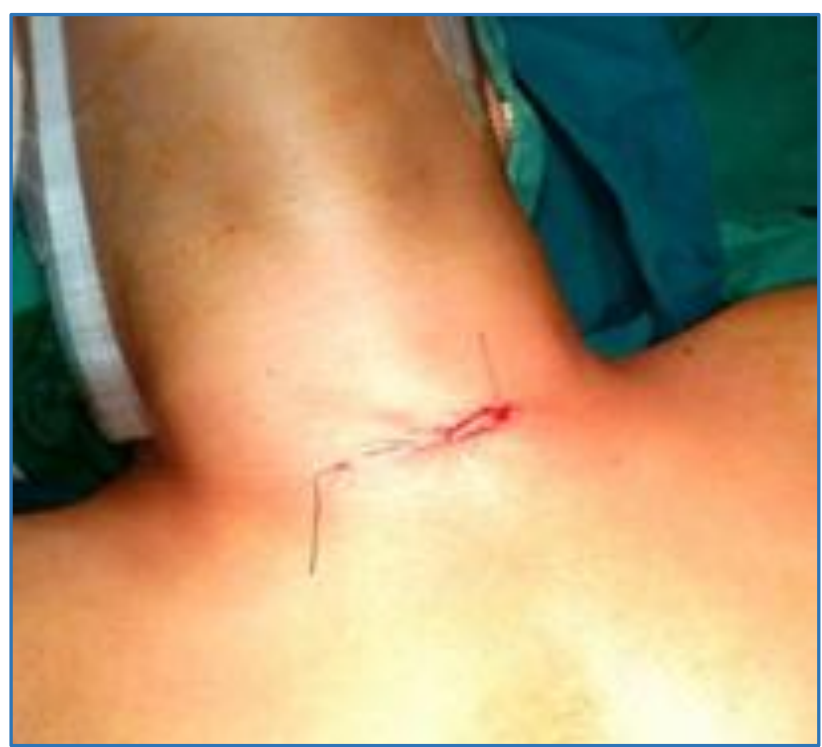

Figure 7. At the End of the Procedure 


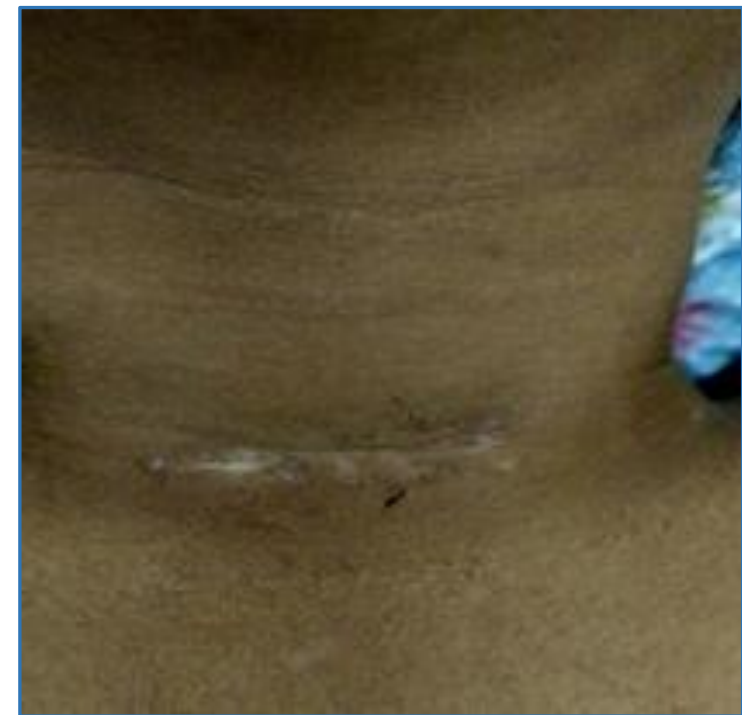

Figure 8. Six months Follow-up

Histopathological examination demonstrated fragments of the cyst lined by keratinised, stratified squamous epithelium, along with adjacent areas of mixed inflammatory cells with foreign body giant cell reaction. No adnexal structures (hair follicles or eccrine glands). No malignant features were present in the cyst wall. This appearance was consistent with epidermoid cyst.

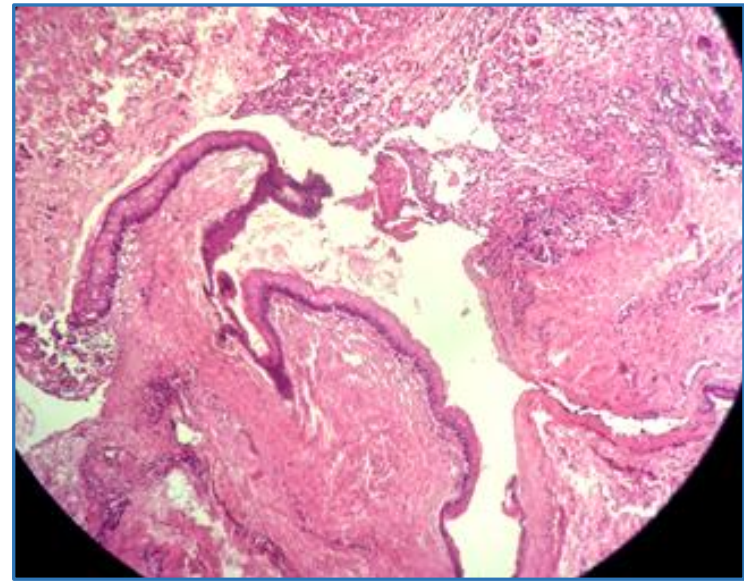

Figure 9. Microscopic View of the Epidermoid Cyst. Cyst wall lined by Keratinising Stratified Squamous Epithelium and Contains Keratin Flakes

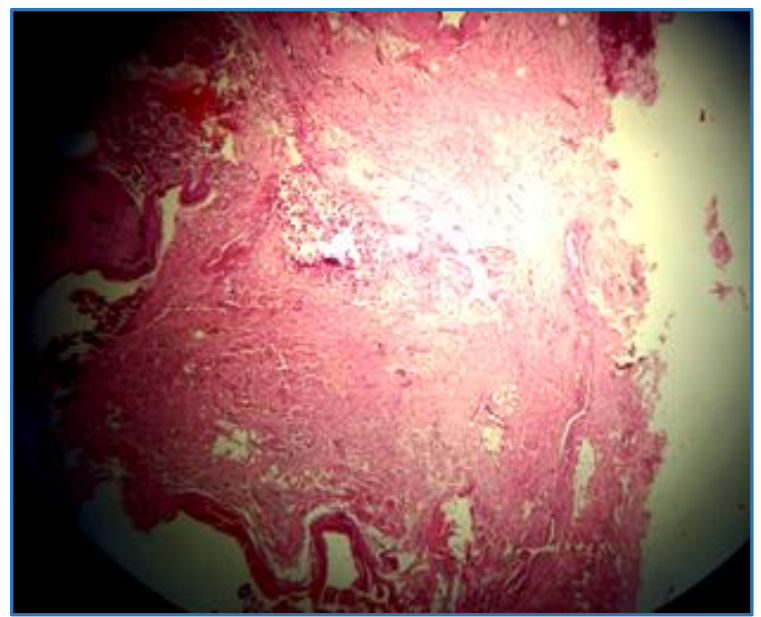

Figure 10. Microscopic View of the Epidermoid Cyst. Cyst wall lined by Keratinising Stratified Squamous Epithelium along with Fatty Tissue
No recurrence was observed in the followup at the $1^{\text {st }}, 3^{\text {rd }}$ and $6^{\text {th }}$ months.

\section{DISCUSSION}

In our ENT practice, cystic masses in the head and neck region are a common clinical presentation. Epidermoid cysts usually present as a cutaneous swelling in the scalp, neck and face.[1] But they are rare in the deeper planes, which is supported by literature references and a thorough review. Dermoid and epidermoid cysts of the head and neck region are rare and constitute only $1.6-6.9 \%$ of all cases in the body.[2]

In a retrospective study among 89 children, only $13.33 \%$ cases of cysts in the head and neck region were found to be epidermoid, compared to $58.88 \%$ of dermoid cysts. [3] Overall only $7 \%$ of all the epidermoid and dermoid cysts are found to occur in the head and neck area, $[4,5] 1.6 \%$ in the oral cavity, and constitutes only $0.01 \%$ of all the oral cysts.[4-6]

In a study at Mayo Clinic by New and Erich, out of the 1,495 cases of dermoid cyst, only 24 were seen intra-orally, at the floor of the mouth.[7] In another study, out of the 191 children treated for congenital cysts and fistula in the neck, only 21 were diagnosed as dermoid cysts.[8] In a 20-year study, it was shown that dermoid and epidermoid cysts consist of only $3.7 \%$ of all congenital non-salivary cysts of the suprahyoid neck in children.[9] Thus, it seems from the review of literature that epidermoid cysts are rare to occur in the head and neck region. The added dilemma in our case being an infected epidermoid cyst.

The differential diagnoses of such swellings in children include thyroglossal duct cyst, thyroid mass, cystic hygroma, cervical bronchogenic cyst and ectopic thymic mass.[10]

Surgical excision of epidermoid cyst is the treatment of choice.[11] As in our case it is done in the operating room and under general anaesthesia.

\section{CONCLUSION}

The diagnosis of an epidermoid cyst can be a dilemma owing to the unusual and misleading clinical presentation, characteristically in our case it being infected. Epidermoid cysts are relatively less common in the head and neck region, and chances of misdiagnosing them are common, hence one should have a high index of suspicion.

We found a preoperative FNAC more informative and supportive in contrast to the general opinion presumed from the study of the existing literature. Imaging modalities like ultrasonography or CT scan can further help in surgical planning.

\section{REFERENCES}

[1] Handa U, Kumar S, Mohan H. Aspiration cytology of epidermoid cyst of terminal phalanx. Diagn Cytopathol 2002;26(4):266-7.

[2] Jham BC, Duraes GV, Jham AC, et al. Epidermoid cyst of the floor of the mouth: a case report. J Can Dent Assoc 2007;73(6):525-8.

[3] Armon N, Shamay S, Maly A, et al. Occurrence and characteristics of head cysts in children. Eplasty 2010;10:e37.

[4] Koca H, Seckin T, Sipahi A, et al. Epidermoid cyst in the floor of the mouth: report of a case. Quintessence Int 2007;38(6):473-7. 
[5] Ozan F, Polat HB, Ay S, et al. Epidermoid cyst of the buccal mucosa: a case report. Contemp Dent Pract 2007;8(3):90-6.

[6] Kandogan T, Koç M, Vardar E, et al. Sublingual epidermoid cyst: a case report. Journal of Medical Case Reports 2007;1:87.

[7] New GB, Erich JB. Dermoid cysts of the head and neck. Surg Gynecol Obstet 1937;65:48-55.

[8] Nicollas R, Guelfucci B, Roman S, et al. Congenital cysts and fistulas of the neck. Int J Pediatr Otorhinolaryngol 2000;55(2):117-24.
[9] Hsieh YY, Hsueh S, Hsueh C, et al. Pathological analysis of congenital cervical cysts in children: 20 years of experience at Chang Gung Memorial Hospital. Chang Gung Med J 2003;26(2):107-13.

[10] Gaddikeri S, Vattoth S, Gaddikeri RS, et al. Congenital cystic neck masses: embryology and imaging appearances, with clinicopathological correlation. Curr Probl Diagn Radiol 2014;43(2):55-67.

[11] Suliman MT. Excision of epidermoid (sebaceous) cyst: description of the operative technique. Plast Reconstr Surg 2005;116(7):2042-3. 